\title{
Dr. ALONSO DE HUERTA CEREZO, EL QUECHUISTA AMIGO DE SANTO TORIBIO
}

\author{
Dr. José Antonio Benito Rodríguez
}

Con el deseo de contribuir al mayor conocimiento de los protagonistas de la Universidad de San Marcos, presento el testimonio del Dr. Alonso de Huerta, Decano de las Facultades de Teologia y Artes de la Universidad de San Marcos, en el proceso de beatificación de Toribio Alfonso Mogrovejo, segundo arzobispo de Lima, en la declaración de 10 de noviembre de $1631^{1}$.

\section{APUNTES BIOGRÁFICOS}

Natural de Huánuco, fue hijo legitimo de Ana Cerezo y Alonso Huerta, antiguo soldado residente en la villa, de donde salió con Miguel de la Serna en 1554 para combatir en Pucra a Hernández Girón. Nuestro protagonista recibió la tonsura clerical en 1585. Desde 1590 fue cura del Cercado, capellán en la iglesia de Copacabana, y luego en la Catedral, predicando en quechua, y por oposición ocupó la cátedra de Lengua desde $1592^{2}$. Desde el 5 de junio de 1593 contó con la autorización de absolver en confesión a los indios de ambos sexos ${ }^{3}$ y en $1630 \mathrm{Fr}$. Buenaventura de Salinas lo declara titular de $\mathrm{ella}^{4}$. Santo Toribio lo recomienda ante el Rey en 1599, 1600 y 1602: "muy buena lengua y la predica y enseña y tiene capellanía designada para ello y predica los domingos y fiestas a los naturales, es muy virtuosa y en extremo aficionado a los indios y les favorece y enseña el catecismo en la puerta de la iglesia"... "en las iglesias y caseríos les dice la doctrina". El 15 de mayo de 1599 el virrey Velasco le acusa de inquietar a los indios reducidos en el Cercado a salir de alli y volver a san Lázaro. Nuestro

\footnotetext{
'Este preciada documento se custodia en el Archivo Arzobispal de Lima, Proceso de Beatificación de Santo Toribio, Legajo 1, ff. 315-330. El autor agradece muy condialmente a Laura Gutiérrez, su directora, por las facilidades prestadas.

${ }^{3}$ Fue examinado en presencia del Arcediano Juan Velázquez, Esteban Fernindez Vozmediano, canónigo, Cristóbal de León, Juan Díaz de Aguilar, Juan Ruia Flores, Hemando de Góngon y Gutéerrez de Cartra eclesísticos expertna en

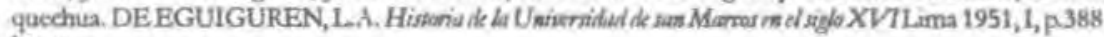

'Ibidem

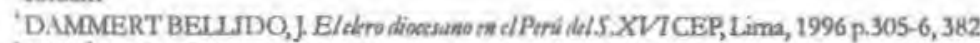

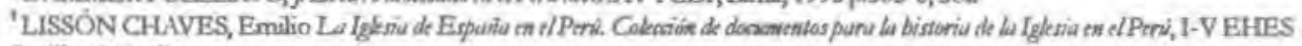
Sevilla $1943-47$.
} 
catedrático dirá del Santo Prelado que "le trató y conoció muy familiarmente en esta ciudad y otras veces caminando fuera de ella yendo su servicio y compañia", siempre pendiente de no causar gastos y molestias a los indios. En cierta ocasión, por la crecida de un rio, durmió el arzobispo sobre un montón de pajas del obraje, abonando, agradecido, su paga correspondiente. Fue uno de los acompañantes en la última visita, vio que era "muy virtuoso y en extremo aficionado a los indios", desaconsejándole esa localidad de Zaña "por ser tierra enferma y cálida y que morian de calenturas por el riguroso calor que entonces hacia". Su relato nos aporta detalles interesantes de la propia vida y familia del Dr. Huerta, tales como los relacionados con su propio padre, quien acompañó al andarín arzobispo, lo concerniente a la parroquia de indios del Cercado o los referentes al traslado de los restos mortales de Santo Toribio desde Zaña a Lima.

Alonso Huerta fue capellán de la fundación de Hernando de Álvarez, con la obligación de enseñat quechua y predicat. Obtuvo por oposición la cátedra de lengua quechua, vacante por fallecimiento del agustino Juan Martínez de Ormachea, 1616. El Arzobispo Lobo Guerreto, en 10 de abril de 1618, lo elogia por examinar bien a los clérigos y religiosos que ocuparian doctrinas de naturales, aunque estima que deben hacerlo en presencia del Prelado para mayor seguridad.

\section{En 1616 publicó en Lima el Arte de la lengua quecbua general de los indios del} Peri'. M. Mendiburu nos recuerda su inteligencia práctica en Ingeniería así como su afición a la medicina natural, trayendo a colación que en el Libro de Actas de la Universidad se opuso al restablecimiento de las cátedras en la Facultad de Medicina trabajando para probar que no era necesario fomentar la enseñanza sobre objeto tan inútil, pues existian yerbas medicinales de sobra en Perú para las enfermedades y heridas y que los indios las conocian mejor que los médicos.

Este espiritu quisquilloso parece que le acompañó durante toda vida si nos atenemos al crecido númeto de expedientes de causas judiciales civiles hasta diezalbergadas en el Archivo Arzobispal de Lima a lo largo de los años 1606 y $1641^{?}$.

Ello no obsta su espiritu generoso y solidatio como revela el hecho de traspasar toda su herencia a la Compañia de Jesús con quien tuvo gran amistad ${ }^{8}$.

\footnotetext{
VARG IS UGARTE, R. LISSÓN 276, 441, 269, 679; Vargas, Impresos 71,3; Angulo 61 n.

"MENIDiBUTU, M, Diccionario Histórico-Bingnifico del Perñ. Lima 1934 VI, 278; [X, 442

'1606, Legajo VI. Exp. 14, Causa seguida por el Dr. Alonso de Huerta contra el racionero Pedeo Maurico por haber entrado a vivir en unas casas de su propiedad y no querénclas entregar ni dar razón de cómo se cntró en ellas (12 I)

1607, Leg VII, 1. Causa seguida por el Dr. Alonso de Huerta contrs el racionero Pedro Mauricio Gonzilez, sobrc la ocupación de una casa y el pago correspondiente (166 I)

1615, Leg,XVI. Exp.18 Causa seguida por Juan Esteban de Montiel, vecino de Lima, contra el Dr. Alonso de Huerta, quuen tiene en su poder un macho que le hurtaron en las fiestas del Corpus, $5 \mathrm{ff}, 1 \mathrm{~b}$
} 


\section{DECLARACIÓN DE ALONSO DE HUERTA}

[F.315]'En la ciudad de los Reyes, a 10 días del mes de noviembre de 1631 años para la dicha información el dicho Br. Francisco de Palma presentó por testigo al Dr. Alonso de Huerta, presbítero, natural. de León de Huánuco, en este arzobispado, catedrático de la lengua general de los indios en esta Real Universidad y Decano de las Facultades de Teologia y Artes, del cual el dicho St. recibio juramento en forma de derecho por Dios Nuestro Señor y por una señal de cruz so cargo del cual prometió de decir verdad y siendo preguntado por el tener de las preguntas del pedimento e interrogatorio declató lo siguiente:

\section{A la primera pregunta}

$1^{9}$. Del buen nacimiento y noble sangre de su genealogía y descendencia y de su limpieza que; que esto no le ensoberbeció ni el oficio y puesto de dignidad tan alta que entonces fue sólo Arzobispo en estos Reinos, antes fue humildísimo en todo trato y conversación, vestido y suma llaneza con todos, así españoles como indios y negros.

Dijo que conoció al Sr. Don Toribio Alfonso Mogrovejo desde que entró en esta ciudad que fue por el año de 81 hasta que murió y le trató y comunicó muy

1619. Leg XXII, Exp.8, Causa que sigue el doctor Alonso de Huerta, presbitero, contra el maestro Juliain de Ios Rios, presbitcro, por mil pesos y ocho reales que le prestó, $30 \mathrm{ff}$

1621, Leg XXVI, Exp.4, Lima, Causa seguida por Alonso Sinchez Ramirez contra el doctor Alonso de Huerta sobre la cancelación del arrendarniento de una tienda, $3 \mathrm{ff}$

Exp. 11 Causa seguida por el capitin Juan Trigo contra el P. Alonso de Huerta, quéen le alquiló un cuarto por un año y no quiere pagarle. $7 \mathrm{ff}$

1624 Leg XXIX, Exp,2,Causa cjecutiva seguida por Jerónimo Roma de Figueroa contra el Dr. Alonso de Huerta por una deuda de 218 pesos que se obligó a pagar al Lic. Martín Sánchez, presbitero, por un préstamo, de quien el querellante tiene poder, $11 \mathrm{f}$.

1630 Leg XXXVI, Exp.27, Los Reyes, duto provocido por el Dr. Feliciano de Vcga, canónigo de la Catedral, provisor 9 vicario general del arzobispado, en razón de que el Dr. Monso de Huerti no quite las mercaderias a los negros e indios vendedores de frutas y otras cosas en la plaza puiblica, por motivo de que hacian mucho ruido enviaindolos a las carceles y otras partes. $2 \mathrm{ff}$.

1633, Leg42, Exp,40, Lima. Causa seguida por Alonso Pacheco contra el De. Aionso de Huerta, quien le debe 255 pesos de a 8 r, 11 f

1634, Leg 43, Exp.11. Los Reyes. Causa que sigue Juan Serrano del Valle, cléngo de menores órdenes, contra el Dr. Alonso de Huerta, presbitero eatedrático de quechua por cantidad de pesos, $46 \mathrm{ff}$.

'51, Exp.22, Causa ejecutiva seguida por el capitán de caballos del tegimiento de Los Reyes don Franciseo José Ysasiga contra los bienes que quedaron del De Alonso de Huerte, de quien ena heredera la Compañia de Jesis, por 282 pesos del censo de unas casas. Contiene además los autos ejecutivos seguidos por Hernando de Larcón, cesionano en causa propia del Lic. Jorge de Andrade contra Ios dichos biencs por 661641 Legpesos. 39 ff

'Con objeto de hacer más inteligible la declaración de nuestro testigo incluyo el Cuestionano integrn del proceso elaborado por el Cabuldo limense, densa sintesis que presenta en nueve capitulos a los informantes y testigos que dechararin ante juez y notario para criviar a Roma y tramitar cl proceso de beatificación. 
familiarmente en esta ciudad y otras veces caminando fuera de ellas yendo en su servicio [315v] y compañía y sabe que fue un varón insigne y de eterna memoria y que fue muy limpio y de sangre ilustre por haber sido cosa muy pública y notoria y haber sido inquisidor apostólico en la ciudad de Granada en España y colegial del colegio mayor de Oviedo en la ciudad de Salamanca y que fue arzobispo todo el tiempo que vivió solo en estos reinos y con todo esto fue humildisimo prelado y muy tratable y manso con todo género de personas y muchas veces le vio este testigo que teniendo ventanas a la plaza y otras en el patrio de sus casas arzobispales y entraba algún indio y negro y persona pobre por la puerta de la calle y que subía hasta la sala asomándose a la puerta del patio si le veía volver $\sin$ haberle hablado le preguntaba que qué quería y cómo se volvía y diciendo la tal persona que le venía [316]

a hablar y le habían despedido desde la sala porque le decían que no le podía hablar le mandaba volver a subir y salia el dicho Sr. Arzobispo hasta la escalera a recibirle y despacharle, en especial si era indios de fuera de esta ciudad lo hacia despachar luego diciendo que no quetía que estuviese en ella porque no enfermase sino que se fuese a su tierra y a todos trataba con mucha llaneza y en su vestir lo era mucho (llano) y asi era amado y querido de todos.

\section{A la segunda pregunta}

De la caridad y amor a Dios pues no se le conoció culpa mortal ni imperfección grave y siempre tuvo celo de la honra de Dios y culto divino y conversión de las almas, siendo acérrimo de su Iglesia en los oficios que tuvo de Inquisidor apostólico y arzobispo.

Dijo que sabe y vio que el dicho Sr. Arzobispo fue muy caritativo y en especial tuvo gran caridad y amor de Dios y nunca se le conoció pecado mortal ni venial ni imperfección y tuvo gran celo de la honra de Dios [316v] y que no fuese ofendido con pecados procediendo contra los que le ofendían y nombrando ministros para confesar los pecados públicos y tuvo gran cuidado de que las iglesias y lugares de Dios fuesen reverenciados y adornados de ornamentos y de cosas limpias para el culto divino y de ministrar que cuidasen de las cosas de las iglesias y hacia las visitas de ellas con muy gran puntualidad inventatiando sus bienes y haciendo que se aumentasen o con su ejemplo y reverenciaba las imágenes y altares como católico defensor de sus iglesias acudiendo en esto a la obligación del oficio pastoral y proveyendo las iglesias de arras porque consagró grandísima suma de ellas [317] sin cansarse un punto en todas las parroquias de su arzobispado y asimismo consagro muchos cálices y patenas $\mathrm{y}$ algunos obispos y bendijo muchos ornamentos e imágenes y capillas y cosas para el culto divino en que se esmeraba con gran cuidado como tan celoso de el. 
En el amor del prójimo fue ardentísimo en el deseo de la salvación de las almas, no perdonando trabajo ni peligro, ni visitando y confirmando, predicando a una a los indios por su propia persona y socorriéndolos en sus necesidades y enfermedades a todos los pobres, dándoles largas limosnas, gastando en esto toda su renta con tanto desinterés que no sabía qué cosa era dinero ni codicia hasta quitar de su propia persona y casa lo necesario. Porque no saliese de ella sin remedio la necesidad sin decir a nadie mala palabra ni desabrida respuesta.

Dijo que sabe que el dicho Sr. Arzobispo fue ardentísimo en el amor y caridad de los prójimos porque por cualquiera indio y pobre que fuese por atraerle al conocimiento de la fe católica y bien de su alma pasara cualquier trabajo como los pasó muy grandes en las visitas de su arzobispado entrando en partes muy remotas y trabajosas, de caminos muy ásperos y fragosos donde nunca había entrado prelado alguno y fue el primero que confirmó el dicho su arzobispado y le visitó todo él muchas veces $[317 \mathrm{v}]$ y confirmó grandisima suma de almas sin llevar ofrenda ni velas ni vendas a nadie porque todas las ponia su señoria de su hacienda y en lugares de españoles las velas que compraban dejaba a las iglesias y capillas donde hacia las confirmaciones que le podía esto valer gran suma de pesos y predicaba a los indios todos los domingos y fiestas por su propia persona estando en esta ciudad a la puerta de la iglesia adonde habiendo acabado predica este testigo a los dichos indios en su lengua por tener obligación de ellos. Socorria muy de ordinario las necesidades de los pobres dándoles muy largas limosnas gastando su renta en ello con tanto desinterés que no sabía qué cosas son de dinero ni le tenía ni le poseía sino eran los derechos que le venían por los despachos de las censuras generales los cuales luego al punto los repartía para que le dijesen de misas a clérigos pobres y esto era cuando no visitaba [318]la ciudad y era tan limosnero que daba las sábanas y frazadas que tenía en la cama y en las doctrinas los tarros y platos de plata y cruz de guión y fuentes para que en las iglesias pobres se hicieren algunos cálices y vinajeras y saliendo de esta ciudad con vajilla de plata volvia ya sin ella, porque toda la daba de limosna y dos veces habiéndole [...] para la caridad. Y dio para un hospital babiéndolos remitido a que fuesen a don Francisco de Quiñones su limosnero, a pedirle, estando a la ventana del patio viendo los bajar por la escalera les preguntó que si les habían dado limosna y respondiéndole que les habian dicho que volviesen otro día que se las [318v]darian, estando una mula suya en el patio de [...] le dijo a uno:

- Llevaos aquella mula y a otro que se llevase un negro [...] y diciéndole que como habia dádolos de aquella manera respondió "despáchenlos y denles la limosna pues los envío allá donde no tengo de darles todo lo que hubiere y fue tan 
limosnero que si no le fuesen a la mano sería necesario pedir para sustentarle porque ninguno llegó a él que saliese desconsolado ni le dijese mala respuesta . Entró en muchas partes sin tener muchas veces qué comer y careciendo de cama y se ponía a cualquier peligro por salvar las almas y convertir las ánimas a la fe católica y estando en un obraje de Paucartambo en la provincia de Chincacoya la segunda semana de [319] cuaresma. yendo visitando su arzobispado en tiempo de grandes aguaceros y lluvias estuvo determinado de entrar la tierra adentro a un ingenio que llaman Guancabamba que por alli hay mucha suma de indios infieles se resolvió a querer entrar alli, a pie y aunque le decian que en tres días que se habian de caminar para llevar al dicho ingenio no habia parte a donde poder hacer dormida por ser la tierra muy cenagosa y áspera y que no habia modo de poder andar a caballo y rehusando los criados que con el dicho St. Arzobispo iban a queter ir sirviéndole dijo no se me da nada que ahi está Huetta que es este testigo que irá con $[319 \mathrm{v}]$ migo y habiéndole dicho este testigo que si iria, le respondió iremos como unos reyes con nuestros bordones y alpargatas que con ello se podrá caminar muy [...] y habiéndose un jueves de pascua de la dominica primera de cuaresma se puso el a decir:

- Ea, vamos. Este testigo le dijo, Vuestra Señoría predicó el domingo, que no se habia de tentar a Dios ni pedirle hiciese milagros y haber de hacer esa jornada es tentarle y pedirle que nos lleve milagrosamente porque según dicen es de malo y el trabajo que se ha de padecer es pedir que haya milagro con nosotros. $\mathrm{Y}$ a esto respondió:

- De suerte que le parece que no es bien que vamos ahora dejemos pues la ida para en tiempo que no sea invierno que entonces entraté allá.

$\mathrm{Y}$ asi quedo mostrando su docilidad y mansedumbre con que procedia y con prudencia negando muchas veces su propia voluntad sin tener gusto en nada y eran en tanta maneta que si comía alguna cosas y se la ponían para que la comiese si se la loaban diciéndole que comiese porque era muy buena no comia más bocado ni lo quería y la daba al que se la había loado, diciéndole pues tome, cómasela, de manera que todo el tiempo que fue arzobispo y gobernó nunca tuvo sosiego ni descanso porque todo fue trabajar y caminar hasta dar la vida por sus ovejas como buen pastor y prelado.

[320v]

\section{A la cuarta pregunta}

La sinceridad y candidez de su ánima fue tanta que en alma tan limpia nunca cupo mala sospecha de nadie ni creía mal que le dijesen de otro, antes volvía por todos y les defendía con modo santo y discreto. 
Dijo que vivía el dicho St. Arzobispo con tanta limpieza de su conciencia y andaba tan ajustado en ella que muy cándido y sincero, en su alma nunca cupió mal sospecha de nadie ni creía mal que le dijesen de otro, sino volvía por todos con su santo modo y no queria ni consentia que en su presencia se dijese mal de nadie ni murmurasen ni hablasen palabras ociosas y que este testigo nunca se las vio al dicho Sr. Arzobispo en todo el tiempo que le trató y comunicó y cuando le decían que fulano había hecho algo, decía:

- Mire que no será así, que hombre honrado es

Y por evitar conversaciones vanas hacía que todas las veces que comía y cenaba le leyesen en un libro debido sin faltar en esto [321]

y todas las veces que acababa de comer o cenar decía un responso por las animas del purgatorio y por el fundador de su colegio de Oviedo donde fue colegial.

\section{A la quinta}

Sus penitencias de abstinencia comiendo poco y desabridamente, sin apetecer regalos ni convites, ayunando y disciplinándose rigurosamente. Temples rigurosos, no durmiendo en cama, gastando lo más del tiempo de día y de noche en oración. Dijo que sabe que fue el dicho Señor Arzobispo muy penitente porque le vio que era de muy poco comer y eso sin regalo ni apetecer cosa que oliese a él [sic] como tiene dicho si le loaban alguna cosa que comía diciendo que estaba buena no comía de ella más bocado y la daba a quien se la loaba diciendo que se la comiese él. Y en las demás penitencias lo principal que tenia era negar su propia voluntad de manera que aunque en una mañana hubiese confirmado mil indios de una vez y a las tres a cuatro de la tarde se sentara a comer cuando había acabado habiendo dicho que iba a reposar un poco y reposar la fiesta y este testigo y los demás criados se iban a comer a medio comer los llamaba [321v]diciendo que estaba su siesta en la iglesia para volver a confirmar y recibir los bienes y cuentas de ella en la iglesia por manera que habiendo dicho que iba a reposar entiende este testigo que hacía escrúpulo de descansar y volvia a trabajar de nuevo. Asi mismo sabe y vio que ayunaba el dicho arzobispo de tal manera que apenas dormia una vez al dia y eso tan poco que si no es milagrosamente con el sustento que comía no pudiera pasar segín el trabajo y abstinencia con que vivía y en ninguna manera recibió regalo alguno de ninguna persona aunque cuando estaba en esta ciudad si veía que habian traido alguna suerte de frutas u otras cosas de poco momento que acertase a ver lo que era en más de ocho dias no comía de aquello pareciéndole que había sido de lo que habian traído [322] 
de fuera y jamás quiso comer ni comió cosa que entendiese que no le habia costado su dinero sino era la procura así de las visitas y esa con mucha moderación y era de tal manera que cuando algunas veces estando en esta ciudad que iba al pueblo de Lurigancho y otros cerca, no siendo tiempo de visita llevaba de comer de su casa y cuando sucedia estar visitando las doctrinas y acertaba a quedarse a comer o a irle a ver alguna persona grave o de importancia que hubiese de comer a su mesa hacía que buscasen al cura y supiesen de él si convidaba a la tal persona porque decían que era que si le había de convidar que él no lo hacía sino llevar procuración para sí y sus criados que eran bien pocos [322v]

y a este testigo le dijo su padre llamado Alonso de Huerta que andando con él algunas veces en las visitas que ya he dicho llegaron perdidos y entrambos dos solos a más de las diez de loa noche en cierta parte de donde sólo habia unos paredones de tierra adonde podian pasar la noche a la inclemencia del cielo animados sin techos y que estaban tan sin comida ni cama que si el padre de este testigo no acertara a llevar un pan que se cuidó le partieran entre ambos comiendo cada uno el medio lo pasara muy trabajosamente aquella noche por haber trabajado todo el día y todo esto lo hacía y padecía con grande contento y alegria y tiene por cierto este testigo que aunque llevaba y tenia cama en algunas partes no dormía en ella y pasó temples muy rigurosos en las visitas y entró en partes muy fragosas a veces [323] sin tener cama y con gran riesgo de la vida y habiendo en cl obraje de Paucartambo enviado todas las cargas y camas a un pueblo cinco leguas del apartado, yendo al dicho pueblo encontraron después de haber caminado dos leguas un riachuelo muy caudaloso por entonces que ninguno se atrevía a pasarlo habiendo pasado por la mañana todo el hato por venir bajo y fue forzoso volver al dicho obraje adonde estando todos sin camas para dormir prestó el obrajero más frazadas para los criados y a la mañana misma de salir de alli pidiendo le pagasen los alquileres de 1 lugar como se hizo no se vio que recibiese de nadie convites ni fuera ellos aunque fuese fiestas algunas porque no las apetecía aunque se hiciese a fondo a las fiestas porque era muy limpio y recatado en todo [323v]

\section{Ala sexta pregunta}

La paciencia y sufrimiento en trabajos y contradicciones sin haberle oido palabra descompuesta ni de enojo y habiéndose visto en grandes y graves peligros, salia de ellos contento y sosegado dando gracias a Dios sin alboroto ninguno.

Dijo que sabe que fue el dicho $\mathrm{Sr}$. Arzobispo muy paciente y sufrido en trabajos y contradicciones que paso porque en ciertos pleitos que tuvo que defender su jurisdicción en tiempo que era virrey de estos reinos don García Hurtado de Mendoza, el cual desbarató y deshizo un pueblo de indios que llamaban 
Pescadores que estaba fundado en el barrio de san Lázaro de la ciudad que tenía una iglesia por parroquia, desbaratando las casas, llevándolos por fuerza a que poblasen el pueblo del Cercado que tienen los Padres de la Compañía de Jesús y habiendo pasado de más de 700 indios que había al dicho pueblo aún no 300 porque se huian y escondian de miedo de que hubo mucha controversia y tuvieron ejecutorias de Su Majestad para que no los pasasen y llevasen por fuerza el dicho virrey por tener un hermano de la dicha [324]

compañia ahínco y hizo estancia en los llevar y diciendo el dicho St. Arzobispo que él tenia su parroquia de clérigo en san Lázaro que era el P. Juan de san Martín y es ya dicho testigo y murió después canónigo de la catedral de Trujillo, respondiendo el dicho Sr. Virrey que pusiesen parroquia de clérigos en el dicho pueblo del Cerca y así señalaron un sitio en que empezaron a fundar iglesia con título de Señor san Lázaro y habiendo dicho al dicho Juan de San Martín que fuese al dicho pueblo a administrar los sacramentos respondió que no quería meterse con padres de la compañia y en esta sazón este testigo estaba recién ordenado de misa y diciéndole el dicho Sr. Arzobispo que fuese allí a ser cura de los indios que se reducían de nuevo al dicho Cercado y habiéndose puesto edictos al dicho curato se opuso a él [324v]este testigo por lo que no hubo otro clérigo que se quisiese oponer por lo que oian decir de parte de los dichos Padres de la Compañia de que ellos harian no hubiese ningún aprovechamiento y con esto no habria clérigo que quisiese ser cura alli y este testigo por obedecer lo que el dicho Sr. Arzobispo le mandaba se opuso y habiendo llevado la nominación al dicho Sr. Virrey para que le presentase al Dr. Castilla oidor que entonces era presidente le dijo a este testigo que le darian buena la presentación y que fuese con este seguro a ser cura alli y administrar los sacramentos a los dichos indios según la licencia que tenía del dicho $\mathrm{Sr}$. Arzobispo el cual le hizo vicario del dicho pueblo del Cercado y de todos los indios que hay; se redujesen como lo fue y habiéndole [325]con que poder hacer una iglesia en mes y medio este testigo la fue levantando para que pudiese decir misa y administrar los sacramentos decentemente en ella y habiendo visto los padres de la compañia la prisa con que la edificaba trataron de impedir el edifico de ella y así le notificaton a este testigo teniéndola a medio cubrir de mangles y esteras de parte del dicho virrey que no prosiguiese con el dicho edificio y que pues no tenia presentación tampoco administrase sacramentos y habiéndolo sabido el dicho Sr. Arzobispo le dio a este testigo su nombramiento de que el solo fuese cura en el dicho cercado que si los Padres de la Compañia tenian alguna licencia de administrar sacramentos la exhibiesen porque el no quería que los administrase en ninguna manera y habiéndoseles notificado [325v]criaron un juez conservador al cual amparó y defendió el dicho St. Virrey de manera que hubo muchas disensiones y pesadumbres cerca de poner en las esquinas de las calles papeles declarando por excomulgado al dicho Sr. Arzobispo Yen esta sazón y tiempo de estas disensiones habiendo fundado el dicho Sr. Arzobispo el colegio seminario en esta ciudad 
conforme al santo concilio de Trento y puesto a las puertas de él su escudo de armas por haberles comprado con su hacienda las casas en que lo fundo el dícho Sr. Virrey se las mandó picar enviando su capitán de la Guarda con soldados para ello y las picaron e hizo poner las de Su Majestad y todas estas pesadumbres y disensiones las llevó y sufrió con gran paciencia el dicho Sr. Arzobispo sin que en ninguna manera se mostrase enojado [326]ni habló palabra descompuesta conformándose siempre con la voluntad de Dios y pidiendo perdón por ellos y este testigo vio que cuando después le vino cédula de Su Majestad con reprensión del virrey por haberle picado las armas y que pudiese poner las suyas dijo: ya están puestas las de Su Majestad y así no quiero poner las mías, sólo se intitule colegio señor de santo Toribio en el cual ha habido y hay muchos estudiantes que han salido sacerdotes y doctos y virtuosos

\section{A la séptima pregunta}

La fortaleza y constancia de su ánimo fue tan singular que con ser humildísimo como está dicho, fue juntamente gravísimo en representar su dignidad y autoridad defendiéndola sin complacer y con quiebra de su honor a las potestades seculares.

Dijo que sabe y vio que el dicho St. Arzobispo tuvo siempre gran fortaleza y constancia en todo cuanto proveia y hacia y con ser tan humilde como está dicho fue gravísimo prelado en representar su autoridad y dignidad arzobispal sin quebrar un punto de lo que [326v] de lo que se le decía y defendía con grandes fuerzas las inmunidades de su iglesia sin atender a humanos respetos por más que al descargo de la conciencia y hacer justicia hasta que en una ocasión en que el corregidor de los indios de esta ciudad a quien favorecía el dicho virrey don García hurtado de Mendoza me dijo habia ahorcado a un hombre que había sacado de la iglesia y por ello lo excomulgó y puso eclesiástico entre dicho y cesión a divinis y lo condenó en cantidad de pesos.

\section{A la octava pregunta}

En la hospitalidad y castidad fue raro ejemplo desde [sic] y por los ejemplos [...] en los testigos parecía nimio en recato para no dar ejemplo ni nota de su persona.

Dijo que sabe y vio que el dicho Sr. Árzobispo. Fue muy casto, puro y compuesto en sus palabras y acciones que se mostraba muy bien la sinceridad que en el alma tenía, según traía su conciencia [327] 
ajustada y limpia y no se le conoció ninguna palabra ni dicho que desdijese de su integridad y limpieza.

\section{A la nueve pregunta}

En letras fue insigne como lo testificarán los que le trataron y lo dicen todos los testigos, concilios provinciales que en su tiempo se celebraron, que sin haber habido otros se ha gobernado con ellos esta monarquía eclesiástica; por lo cual le hontó Su Santidad con cartas favorables. Por todo lo cual la Majestad Humana del Rey Nuestro Señor se sirvió de honrarle con sus cartas y mucho más la Majestad Divina, testificando Su Santidad con patentes milagros, en vida y muerte y con general y común opinión en todos de santo y de vida inculpable y de ejemplo de prelados y así en la traslación de su cuerpo concurrían a procurar reliquias de él, como de santo, aclamándole todos por tal, sin haberlo habido en su vida o muerte algo en contrario. Por todo lo cual y lo que más en esta causa puede ser necesario conforme a derecho que habemos por reproducido y expreso.

Dijo que sabe que el dicho St. Arzobispo. Fue varón muy docto en derechos de manera que ninguna dificultad que se ofreciese dejaba luego al punto de verla y hallarla en los derechos y no proveía cosa que no fuese habiéndola visto y fundada en el derecho de manera que en cuantos autos proveia era costumbre general decir los proveía en cuanto habia lugar de derecho y como se descargase la conciencia y más se sirviese en su tiempo se celebraron muchos concilios provinciales y especialmente que el del año de 83 en que asistieron 7 obispos sufragáneos y en él se sentaron muchos decretos para el bien de las iglesias y reformación de costumbres por el cual se gobierna esta monarquía eclesiástica el cual está aprobado por Su Santidad y más lo ejecutar por Su Majestad y así mismo hizo que se tradujese las oraciones, doctrina cristiana, catecismo y confesionario de lengua castellana en la lengua general de los indios y la aymará con que están muy bien doctrinados e instruidos en nuestra Santa Fe Católica y mandaba que todos los curas del Arzobispado lo tuviesen en su poder para este efecto y que personalmente les enseñasen la doctrina cristiana y celebró muchos sínodos conforme al Santo Concilio de Trento y breves apostólicos sin dejarlos un punto porque era muy observante del dicho Concilio y bulas de Su Santidad. Fundó un convento [328] de monjas de Santa Clara en esta ciudad procurando muchas limosnas para él, el cual es uno de los más ricos y graves de esta ciudad donde se profesa mucho recogimiento y virtud y así la santa sede apostólica le hontó mucho con sus 


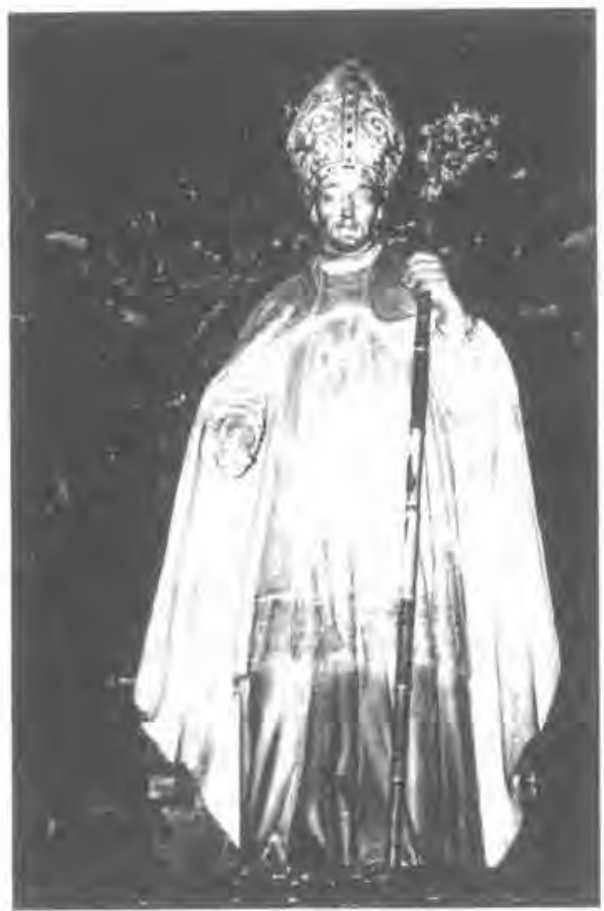

Santo Toribio Gran Amigo del Quechuista Huerta según la estatua de su capilla en la catedral de Lima cartas favorables en que le loaba el celo con que haria por el bien de las iglesias y Nuestro Señor así mismo le ha honrado en vida y muerte con general y común opinión de santo y como a tal le aclaman y llaman el santo arzobispo y todos lo entienden por él sin que ninguna persona lo ignore por ser prelado de gran ejemplo y de loa, inculpable y cuando murió en la villa de Saña que fue Jueves Santo en la tarde, con haberle prevenido delante de este testigo, del vicario que era de la ciudad de Trujillo que no fuese en aquel tiempo [328v]a la dicha villa de Saña consagrar los santos óleos por ser tierra muy enferma y cálida y que morian de calentura por el riguroso calor con que entonces hacía y andaba este testigo en aquella cuaresma por aquellas doctrinas y valle de Trujillo en compañia del dicho St. Arzobispo veía como le persuadian a que entonces no fuese a ella sino que los consagrase en la ciudad de Trujillo y por obligarle a ello le decian que no había de poder juntarse los sacerdotes necesarios para la dicha consagración y que en Trujillo los había bastantemente] y todo el tiempo que anduvo indiferente en si iria o no a la dicha villa de Saña le fue siguiendo este testigo hasta que por haberle escrito el dicho vicario de Saña que de Guadalupe y otros pueblos cercanos podrian juntar copias de sacerdotes [329]

para la dicha consagración, se resolvió a no querer ir a Trujillo sino aún de ir a Saña posponiendo todos los peligros y riesgos que le decían que habia de padecer y fue de manera que este testigo dijo que se resolvía a ir a la dicha villa pretendiendo no pasar las dichas incomodidades se determinó a volverse a esta ciudad de los Reyes adonde después de haber llegado a ellas lunes después del domingo de cuasimodo llegó 1 nueva de cómo el dicho día de jueves santo habia muerto y abriéndole para embalsamar el cuerpo hallaron que en el vientre no tenía cosa de comida sino muy limpias las tripas y después trayéndolo al cabo de un año a esta ciudad vio que llegó [329] el cuerpo entero e incorrupto salvo un poquito de la punta de la nariz que le faltaba y con un olor y suavidad que todos los que llegaban, que eran muchos, a reverenciarlo y casi queriéndose aprovechar 
para reliquias de las vestiduras y mortajas con que vino que era cosa sobrenatural y que el dicho día que entró el cuerpo hubo gran sentimiento en todos generalmente así españoles como negros e indios, manifestando el gran amor que tenían al dicho St. Arzobispo como a prelado y padre que tanto los queria y amaba y el dia de hoy prevalece la opinión de santo en que ha estado y desean verle canonizado por sus muchos mêritos $y$ virtudes $y$ ha oído decir que Nuestro Señot ha hecho muchos [330] milagros por intercesión e invocación del dicho St. Arzobispo y que lo que ha dicho y declarado es la verdad por el juramento que hizo y que es de edad de 66 años y nole tocan las generales de la ley y lo firmó

Fdo. Don Juan de Cabrera, El doctor Alonso De Huerta, Ante mí El Lic. Diego de Morales. 